\title{
SIMULATION OF THE SPECTRA OF THE TRANSVERSE KERR EFFECT OF MAGNETIC NANOCOMPOSITES CoFeZr- $\mathrm{Al}_{2} \mathrm{O}_{3}$
}

\author{
M.M. Yashin ${ }^{1,2}$ \\ ihkamax@mail.ru \\ A.N. Yurasov ${ }^{1}$ \\ alexey_yurasov@mail.ru \\ E.A. Ganshina ${ }^{3}$ \\ V.V. Garshin ${ }^{3}$ \\ D.V. Semenova ${ }^{1}$ \\ Kh.B. Mirzokulov ${ }^{1,4}$ \\ G.E. Danilov ${ }^{3}$ \\ ${ }^{1}$ MIREA-Russian Technological University, Moscow, Russian Federation \\ ${ }^{2}$ Bauman Moscow State Technical University, Moscow, Russian Federation \\ ${ }^{3}$ Lomonosov Moscow State University, Moscow, Russian Federation \\ ${ }^{4}$ Samarqand Branch, Tashkent University of Information Technologies \\ named after Muhammad al-Khwarizmi, Samarqand, Republic of Uzbekistan
}

\begin{abstract}
The magneto-optical properties of magnetic nanocomposites have been studied in the study of spectral dependences of the transverse Kerr effect (TKE). Experimental preparation of nanocomposites formed from $\mathrm{CoFeZr}$ and $\mathrm{Al}_{2} \mathrm{O}_{3}$ alloys at different component concentrations by ion-beam sputtering is discussed. Discuss various methods of the theoretical study of nanocomposites depending on the concentration of ferromagnetic components. The spectral dependences of TKE at low concentrations of the metal component are investigated. Spectral dependences of the Kerr transverse effect are simulated in the framework of the TKE are compared taking into account the size effect at different values of the nanocomposite granule size. There is a good qualitative and quantitative agreement between experimental and theoretical spectral dependences of TKE. In addition, in this paper, we note both practical and fundamental importance of the results. The possibilities of using such nanocomposite materials are discussed
\end{abstract}

Keywords

Magnetic nanocomposite, the transverse Kerr effect, the dependence of the spectral method the Maxwell - Garnett effective medium size effect

Introduction. Currently, studies of the optical and magneto-optical properties of nanocomposites are very relevant [1-5]. Under the nanocomposite in the general sense refers to a multicomponent solid material, in which at least one of the 
M.M. Yashin, A.N. Yurasov, E.A. Ganshina, V.V. Garshin

components in one, two or three dimensions have dimensions not exceeding $100 \mathrm{~nm}$. Another possible definition of a nanocomposite can be a structure that consists of a set of repeating component layers (phases), the distance between which is measured in tens of nanometer. Such structures can significantly enhance such effects as tunnel magnetoresistance, the transverse Kerr effect (TKE), magneto-optical activity, anomalous optical absorption, anomalous Hall effect, etc. These effects are of both fundamental and practical interest in a wide range of applications. For example, it is possible to create anodes from silicon nanospheres and carbon nanoparticles for lithium batteries. Anodes made from a silicon-carbon nanocomposite are much more closely attached to the lithium electrolyte, which leads to a decrease in the time of charging or discharging the device. It is possible to produce conductive paper from cellulose nanocomposites, which is very promising for creating a flexible battery. It is also possible to use nanocomposites to obtain thermoelectric materials that demonstrate the combination of high electrical conductivity with low thermal conductivity [6-7].

Another promising area of research is the creation of graphene-based nanocomposite materials. These structures can be used in the production of components of aircraft, which must remain both light and resistant to physical effects. And this is not all possible areas of application of nanocomposites. Thus, the work is relevant and is associated with a promising area of research.

The purpose of the research is to solve an actual problem: modeling the magneto-optical properties of nanocomposites in the visible and near-IR ranges.

Experimental data. The studied samples were obtained by the method of ion-beam sputtering [8]. This is a process of deposition of materials in a vacuum, in which the flow of deposited particles is obtained by bombarding the surface of the original sprayed material with accelerated ions on a substrate heated to a certain temperature. The ion source is either an independent glow discharge or non-self-sustained discharge plasma. Beam extrusion and ion acceleration to the required energy occurs in a special ion-optical system. Thus films of heterogeneous systems based on ferromagnetic alloy were obtained $\mathrm{Co}_{45} \mathrm{Fe}_{45} \mathrm{Zr}_{10}$ and alumina on cellulose substrates. The growth of bulk composites $\left(\mathrm{Co}_{45} \mathrm{Fe}_{45} \mathrm{Zr}_{10}\right)_{X}\left(\mathrm{Al}_{2} \mathrm{O}_{3}\right)_{100-X}$ was carried out in an argon atmosphere. There $X$ is the volume concentration of the magnetic component. Electron microscopic structural studies of the films obtained showed that the composite $\left(\mathrm{Co}_{45} \mathrm{Fe}_{45} \mathrm{Zr}_{10}\right)_{X}\left(\mathrm{Al}_{2} \mathrm{O}_{3}\right)_{100-X}$ in the plane of the substrate is a metal granule randomly distributed in the dielectric matrix [8].

The magneto-optical properties were studied in equatorial geometry; in this case, the magnetization vector is perpendicular to the plane of incidence of light 
and parallel to the sample surface. The transverse Kerr effect consists of changing the intensity of the reflected p-polarized light when the sample is magnetized. The effect appears only for the $p$-component and is zero for light polarized perpendicular to the plane of incidence ( $s$-component). Directly in the experiment, the relative change in the intensity of the reflected $p$-polarized light from samples placed in an alternating magnetic field was measured [5]:

$$
\rho_{\omega}(H)=[I(H)-I(-H)] /(2 I(0)),
$$

where $I(H)$ is the intensity of reflected radiation in the presence of a magnetic field; $I(0)$ is the intensity of reflected radiation without a magnetic field.

A schematic diagram of an experimental setup for recording TKE spectra is shown in Fig. 1.

Fig. 1. Schematic diagram of the installation for measuring the spectral dependences of the TKE of the studied nanocomposites $\left(\mathrm{Co}_{45} \mathrm{Fe}_{45} \mathrm{Zr}_{10}\right)_{X}\left(\mathrm{Al}_{2} \mathrm{O}_{3}\right)_{100-X}$ : $\bar{B}$ is external magnetic field; 1 the broadband source of electromagnetic radiation; 2 mini spectrometer; 3 studying nanocomposite;

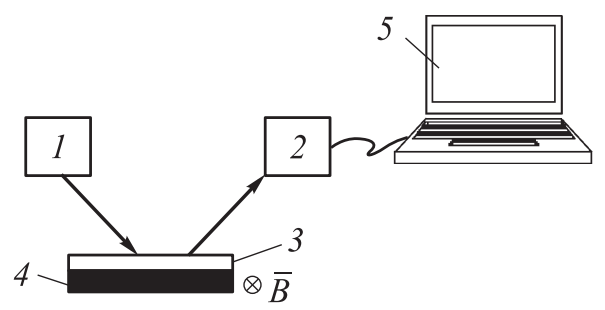
4 glass substrate; 5 PC

As a result of the experiment, spectral TKE dependences $(\rho \omega(E))$ of the studied nanostructured samples with different concentrations of the magnetic component were obtained $X$ (Fig. 2).

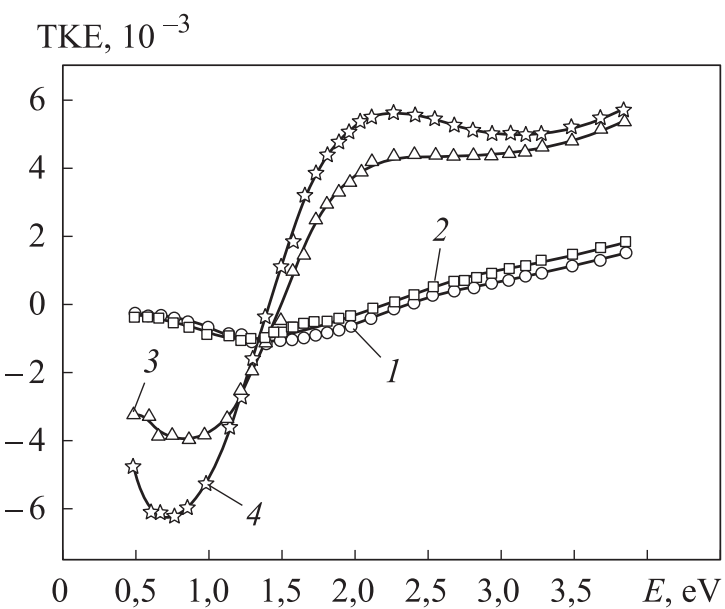

Fig. 2. TKE spectral dependences for nanocomposites $\left(\mathrm{Co}_{45} \mathrm{Fe}_{45} \mathrm{Zr}_{10}\right)_{X}\left(\mathrm{Al}_{2} \mathrm{O}_{3}\right)_{100-X}$ at a concentration of $X=18.5(1), 23.4(2), 52.4$ (3) and $62.1 \%$ (4) 
M.M. Yashin, A.N. Yurasov, E.A. Ganshina, V.V. Garshin

Analyzing the dependencies shown in Fig. 1, it can be argued that percolation finally takes place in the system in the region of more than $50 \%$ of the magnetic component. It is at such concentrations of the metal component that ferromagnetic nanocomposites can be asserted, and at low concentrations, it is more correct to speak of superparamagnetism. We model the TKE spectra of these nanostructures within the Maxwell - Garnett approximation, which works well in the low concentration range [7].

Simulation of the spectra of the transverse Kerr effect. To calculate the TKE of nanocomposites, it is convenient to use the theory of an effective medium. Currently, there are several methods for describing an effective nanocomposite medium. These methods are applied depending on the concentration of the metal component. For small values of $X$, Maxwell - Garnett method [9] is used, with medium concentrations, Bruggemann method [10], and in a wide range of concentration values, taking into account the probabilistic approach, the symmetrical Maxwell - Garnett method [11]. It should be noted that the listed methods do not work in the field of percolation transition. The structures considered in the work have the indicated transition in electrical properties at $X=0.43$ (43\%) [8], but in reality, it is finally carried out along the entire set of properties to a $50 \%$ concentration of the magnetic component.

For the study of the magneto-optical properties of the selected sample with a small value $X=0.185(18.5 \%)$. While TKE is calculated by the formula [12-13]:

$$
\rho_{\omega}=\left(A \gamma_{1}+B \gamma_{2}\right) \frac{2 \sin 2 \varphi}{A^{2}+B^{2}} \text {. }
$$

Here $\quad A=\varepsilon_{\text {eff } 2}\left(2 \varepsilon_{\text {eff } 1} \cos ^{2} \varphi-1\right) ; \quad B=\cos ^{2} \varphi\left(\varepsilon_{\text {eff } 2}^{2}-\varepsilon_{\text {eff } 1}^{2}+1\right) \varepsilon_{\text {eff } 1}-1 ; \quad \varepsilon=$ $=\varepsilon_{\text {eff } 1}-i \varepsilon_{\text {eff } 2} ; \gamma=\gamma_{1}-i \gamma_{2}=\gamma_{\text {eff }}$ are diagonal and off-diagonal components of the dielectric constant of a nanocomposite, which are calculated in the framework of the effective medium theory; $\varphi$ is light angle.

The TKE spectral dependence was constructed (Fig. 3) of the nanocomposite under study, for which Maxwell - Garnett effective medium method was used. The suspension of spherical particles is considered CoFeZr with $\varepsilon_{1}$ in $\mathrm{Al}_{2} \mathrm{O}_{3}$ medium with dielectric constant $\varepsilon_{0}$ particles. In the framework of Maxwell - Garnett approximation and taking into account the smallness of the particles, the condition of the effective medium makes it possible to write the equation for the dielectric constant:

$$
\varepsilon^{M G}=\varepsilon_{0} \frac{\varepsilon_{1}+2 \varepsilon_{0}+2 X\left(\varepsilon_{1}-\varepsilon_{0}\right)}{\varepsilon_{1}+2 \varepsilon_{0}-X\left(\varepsilon_{1}-\varepsilon_{0}\right)} .
$$


Similarly, the off-diagonal compoTKE, $10^{-3}$ nents of the nanocomposite dielectric constant tensor are calculated [9].

The calculated TKE spectral dependence differs significantly from the experimental one, especially in the near-IR spectral range, where the contribution of intraband transitions is still large. To reduce the differences in this range, the first step must take into account the contribution of the semiclassical size effect [14-16]. This effect is due to the geometric constraint on the effective electron mean free path, i.e., scattering on the surfaces of the

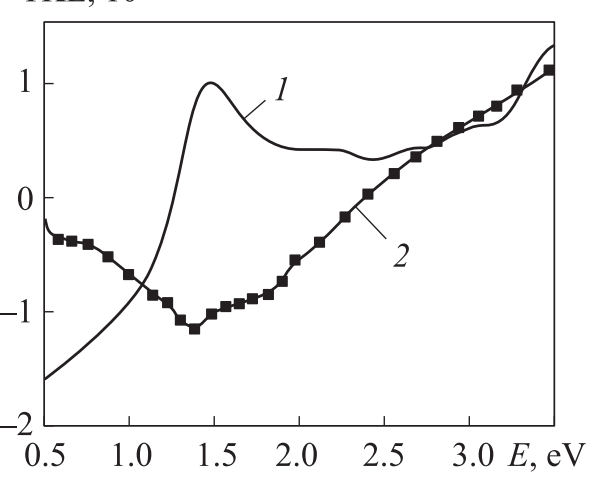

Fig. 3. The calculated TKE spectral dependences at a concentration $X=0.185$ (18.5\%) (1) in comparison with the experimental spectrum (2) granules, as well as the possible size distribution of magnetic particles [16].

In the framework of the effective medium theory, the task is reduced to finding the effective dielectric constant tensor $\varepsilon_{\text {mod. }}$. For ferromagnetic structures, the dielectric constant is defined as diagonal $\varepsilon_{x x}$, so and non-diagonal $\varepsilon_{x y}$ components of the permittivity tensor $\varepsilon_{m o d}$ of the medium. Taking into account the size effect in the expressions for $\varepsilon_{x x}=\varepsilon$ and $\varepsilon_{x y}=-i \gamma$ calculating the components of the dielectric constant tensor reduces to determining the electron men free time in a nanocomposite granule $\left(\tau_{\text {part }}\right)$ and the corresponding time in a massive sample $\left(\tau_{b u l k}\right)$ due to collisions with the surface of the granules:

$$
\frac{1}{\tau_{\text {part }}}=\frac{1}{\tau_{\text {bulk }}}+\frac{v_{F}}{r_{0}}
$$

where $v_{F}$ is Fermi velocity; $r_{0}$ is nanocomposite particle size. Drude - Lorentz law describes the frequency dependence of intraband conductivity. Given the size effect, the dielectric constant is determined by the expression

$$
\varepsilon_{\text {mod }}=\varepsilon^{M G}+\frac{\omega_{p}^{2}}{\omega\left(\omega+i \tau_{\text {bulk }}\right)} \frac{\omega_{p}^{2}}{\omega\left(\omega+i \tau_{\text {part }}\right)},
$$

where $\omega_{p}$ is plasma frequency; $\omega$ is light frequency. Similarly, using Drude Lorentz law, the off-diagonal $\varepsilon_{x y}=\gamma$ components of the dielectric constant tensor are calculated:

$$
\gamma_{\text {mod }}=\gamma_{0}+\frac{4 \pi \sigma_{x y}^{\text {bulk }} / \tau_{\text {bulk }}^{2}}{\omega\left(\omega+i / \tau_{b u l k}\right)^{2}}-\frac{4 \pi \sigma_{x y}^{g r} / \tau_{\text {part }}^{2}}{\omega\left(\omega+i / \tau_{\text {part }}\right)^{2}} .
$$


Here $\quad \sigma_{x y}^{b u l k}=4 \pi M_{s} R_{b u l k} / \rho_{b u l k}^{2} ; \quad \sigma_{x y}^{g r}=4 \pi M_{s} R_{g r} / \rho_{g r}^{2}, \quad M_{s} \quad$ is saturation magnetization, $R_{g r}$ is coefficient of anomalous Hall effect (AHA), pbulk is resistivity of a massive sample, $\rho_{g r}$ is resistivity of a granule, $\rho_{g r}=\rho_{b u l k}\left(1+l / r_{0}\right)$. Particle size affects both AHA and resistivity. The effect of the size effect on the coefficient of AHA granules can be written as [17]:

$$
R_{g r}=R_{b u l k}+0.2 R_{s} \frac{l}{r_{0}}\left(1+\frac{l}{r_{0}}\right)
$$

where $R_{s}$ is coefficient AHA of the material of the surface of the granules.

TKE, $10^{-3}$

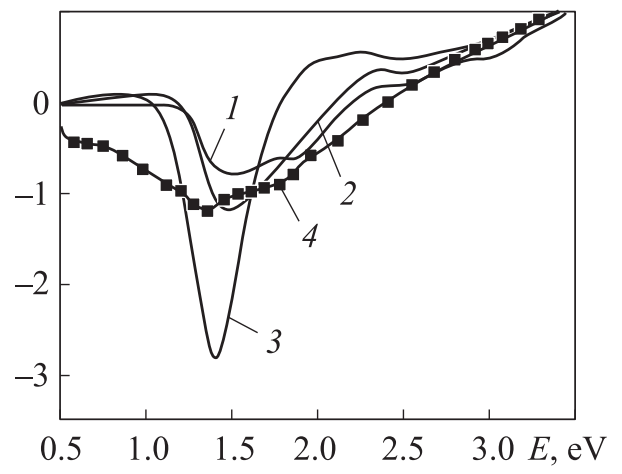

Fig. 4. The calculated spectral dependences of the TKE of a nanocomposite at a concentration of $X=18.5 \%$ taking into account the size effect values of granule sizes $r_{0}=1(1), 1.2(2)$ and $2 \mathrm{~nm}(3)$, experimental data $(4)$

According to formulas (1)-(6), the spectral dependence of the TKE of the nanocomposite under study was calculated taking into account the size effect for different values of the granule size of the nanocomposite under study (1, 1.2 and $2 \mathrm{~nm}$ ). The results are presented in Fig. 4 . There is a good agreement between experimental and theoretical TKE curves. The discrepancies are due to the need to take into account the form factor (a measure of the ellipticity of nanocomposite granules), as well as the possible distribution of particle sizes [16-18]. In this case, based on Fig. 4, the optimal value of the granule size $r_{0}$ is $1.2 \mathrm{~nm}$.

Further, for a given value $r_{0}=1.2 \mathrm{~nm}$, the Maxwell - Garnett method was used to calculate TKE at $X=25$ and $30 \%$, since this method works well for these concentrations. The spectral dependences of the transverse Kerr effect in comparison with the spectrum at $X=18.5 \%$ are shown in Fig. 5. With an increase in the concentration of the metal component of the nanocomposites under study, an increase in energy efficiency is observed, which agrees well with the experimental data (see Fig. 2). Here the limits of applicability of the method are reached; high concentrations can only be described using Bruggemann method and the symmetrized Maxwell - Garnett method.

It should be noted that the Maxwell - Garnett effective medium method describes well the magneto-optical properties of nanocomposites at low concentrations of the metal component. It should also be noted that the 
TKE, $10^{-3}$

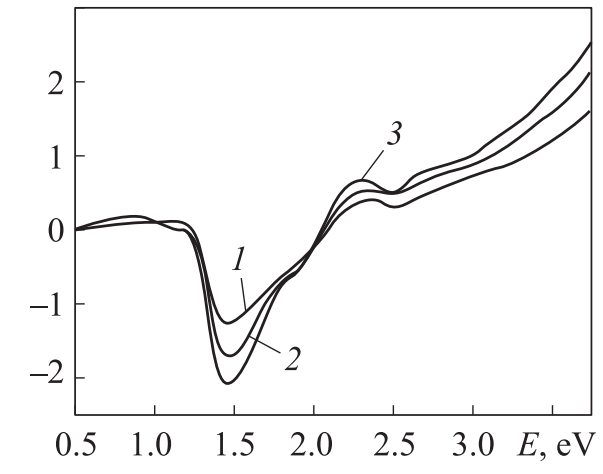

Fig. 5. The spectral dependences of the TKE of a nanocomposite taking into account the size effect $\left(r_{0}=1.2 \mathrm{~nm}\right)$ at a concentration $X=18.5(1), 25(2)$ and $30 \%(3)$
TKE, $10^{-3}$

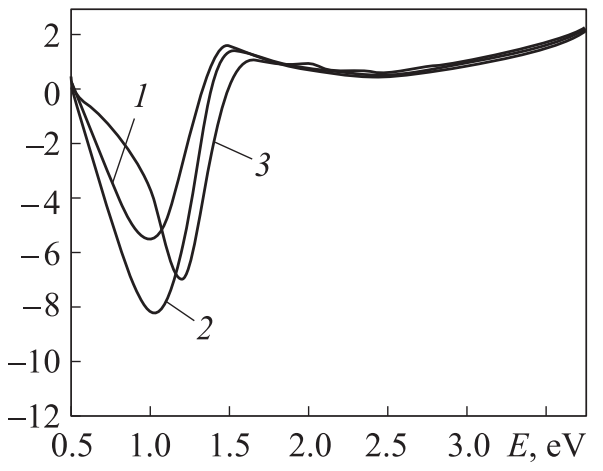

Fig. 6. The spectral dependences of the TKE of the nanocomposite taking into account the size effect $(X=30 \%)$ at values $r_{0}=10(1), 6(2)$ and $4 \mathrm{~nm}(3)$

qualitative and quantitative agreement between the obtained experimental and model TKE spectra at concentrations $X$ is below the percolation threshold.

The types of spectra of TKE nano-composites are studied with changing particle size. In this case, the limiting concentration value was chosen for Maxwell - Garnett approximation $X=30 \%$ for different values of particle size $r_{0}=4,6$ and $10 \mathrm{~nm}$ (Fig. 6). With an increase in the particle size value, the TKE spectral dependencies tend to the form of TKE dependences without taking into account the size effect (see Fig. 3). This result agrees well with formulas (4) and (5). Thus, the obtained data clearly demonstrate the limiting cases of using Maxwell - Garnett effective medium method for calculating the magneto-optical properties of nanocomposites using the TKE example. For further studies of nanocomposites with a high concentration of the $X$ metal component, it is necessary to use other effective medium methods [9-11].

Conclusion. The magnetic and optical TKE of the magnetic nanocomposite $\left(\mathrm{Co}_{45} \mathrm{Fe}_{45} \mathrm{Zr}_{10}\right)_{X}\left(\mathrm{Al}_{2} \mathrm{O}_{3}\right)_{100-X}$ was simulated using Maxwell - Garnett effective medium method taking into account the size effect. When comparing the experimental and theoretical calculated spectral TKE dependences for the concentration of $18.5 \%$ of the metal component, the optimal average size of the granule was found, this is $1.2 \mathrm{~nm}$. It is shown that it is the change in the size of the granules, and not the concentration of the metal component that makes the main contribution to the TKE spectra in the near-IR spectral range. The analysis performed allows us to predict the optical and magneto-optical properties of nanoscale films, which is important for the selection of materials 
M.M. Yashin, A.N. Yurasov, E.A. Ganshina, V.V. Garshin

with desired properties. The results of this work are of great interest for the further study of the optical properties of nanostructures and the search for promising materials with specified properties. Thus, the results obtained are of both fundamental and practical interest [19-20].

\section{REFERENCES}

Translated by K. Zykova

[1] Foster L.E. Nanotechnology: science, innovation, and opportunity. Prentice Hall, 2005.

[2] Alfimova M.M. Zanimatelnye nanotekhnologii [Entertaining nanotechnologies]. Moscow, Binom Publ., 2015.

[3] Gusev A.I. Nanomaterialy, nanostruktury, nanotekhnologii [Nanomaterials, nanostructures, nanotechnologies]. Moscow, FIZMATLIT Publ., 2009.

[4] Vyzulin S.A., Gorobinskii A.V., Kalinin Yu.E., et al. Ferromagnetic resonance, magnetic properties, and resistivity of $(\mathrm{CoFeZr})_{x}\left(\mathrm{Al}_{2} \mathrm{O}_{3}\right)_{1-x} / \mathrm{Si}$ multilayer nanostructures. Bull. Russ. Acad. Sci. Phys., 2010, vol. 74, iss. 10, pp. 1380-1382.

DOI: https://doi.org/10.3103/S1062873810100151

[5] Gan'shina E.A., Vashuk M.V., Vinogradov A.N., et al. Evolution of the optical and magnetooptical properties of amorphous metal-insulator nanocomposites. J. Exp. Theor. Phys., 2004, vol. 98, iss. 5, pp. 1027-1036. DOI: https://doi.org/10.1134/1.1767571

[6] Balabanov V.I. Nanotekhnologii. Nauka budushchego [Nanotechnologies. Science of the future]. Moscow, Eksmo Publ., 2009.

[7] Mikhaylov M.D. Sovremennye problemy materialovedeniya. Nanokompozitnye materialy [Modern problems of materials science. Nanocomposite materials.]. St. Petersburg, SPbGPU Publ., 2010.

[8] Aleshnikov A.A., Kalinin Yu.E., Sitnikov A.V., et al. Magnetic properties of multilayer structures based on $\left(\mathrm{Co}_{45} \mathrm{Fe}_{45} \mathrm{Zr}_{10}\right)_{X}\left(\mathrm{Al}_{2} \mathrm{O}_{3}\right)_{100-X}$ nanocomposites. Perspektivnye materialy, 2012, no. 5, pp. 68-75 (in Russ.).

[9] Yurasov A.N., Yashin M.M. The effective medium theory as a tool for analyzing the optical properties of nanocomposites. Rossiyskiy tekhnologicheskiy zhurnal [Russian Technological Journal], 2018, vol. 6, no. 2, pp. 56-66 (in Russ.).

[10] Bruggeman D.A.G. Berechnung verschiedener physikalischer Konstanten von heterogenen Substanzen. I. Dielektrizitätskonstanten und Leitfähigkeiten der Mischkörper aus isotropen Substanzen. Ann. Phys., 1935, vol. 416, iss. 8, pp. 665-679. DOI: https://doi.org/10.1002/andp.19354160802

[11] Granovsky A., Kuzmichev M., Clerc J.P. The symmetrised Maxwell - Garnett approximation for magneto-optical spectra of ferromagnetic composites. J. Magn. Soc. Japan, 1999, vol. 23, pp. 382-386.

[12] Dodge M.J. Refractive Index. In: Handbook of laser science and technology. Vol. IV. Optical materials. P. 2. CRC Press, 1986.

70 ISSN 1812-3368. Вестник МГТУ им. Н.Э. Баумана. Сер. Естественные науки. 2019. № 5 
Simulation of the Spectra of the Transverse Kerr Effect of Magnetic Nanocomposites CoFeZr- $\mathrm{Al}_{2} \mathrm{O}_{3}$

[13] Buravtsova V., Gan'shina E., Lebedeva E., et al. The features of TKE and FMR in nanocomposites-semiconductor multilayers. SSP, 2011, vol. 168-169, pp. 533-536. DOI: https://doi.org/10.4028/www.scientific.net/SSP.168-169.533

[14] Khanikaev A., Granovskii A., Clerc J.P. Influence of the size distribution of granules and of their attractive interaction on the percolation threshold in granulated alloys. Phys. Solid State, 2002, vol. 44, iss. 9, pp. 1611-1613. DOI: https://doi.org/10.1134/1.1507232

[15] Landau L.D., Lifshits E.M. Kurs teoreticheskoy fiziki. T. 8. Elektrodinamika sploshnykh sred [Course of theoretical physics. Vol. 8. Electrodynamics of continuous media]. Moscow, Nauka Publ., 2017.

[16] Yurasov A.N. About distribution on the granule size in nanocomposites. Rossiyskiy tekhnologicheskiy zhurnal [Russian Technological Journal], 2016, no. 1 (10), pp. 25-27 (in Russ.).

[17] Vedyaev A.V., Granovskii A.B., Kalitsev A.V., et al. Anomalous Hall effect in granular alloys. J. Exp. Theor. Phys., 1997, vol. 85, iss. 6, pp. 1204-1210.

DOI: https://doi.org/10.1134/1.558394

[18] Ganshina E., Granovsky A., Gushin V., et al. Optical and magneto-optical spectra of magnetic granular alloys. Physica A, 1997, vol. 241, iss. 1-2, pp. 45-51.

DOI: https://doi.org/10.1016/S0378-4371(97)00057-5

[19] Chaplygin Yu.A., ed. Nanotekhnologii v elektronike [Nanotechnologies in electronics]. Moscow, Tekhnosfera Publ., 2016.

[20] Erlikh G. Malye ob"ekty — bolshie idei. Shirokiy vzglyad na nanotekhnologii [Small objects are big ideas. A broad view of nanotechnology]. Moscow, Binom Publ., 2012.

Yashin M.M. - Assistant Lecturer, Department of Nanoelectronics, MIREA-Russian Technological University (Vernadskogo prospekt 78, Moscow, 119454 Russian Federation); Assistant Lecturer, Department of Physics, Bauman Moscow State Technical University (2-ya Baumanskaya ul. 5, str. 1, Moscow, 105005 Russian Federation).

Yurasov A.N. - Dr. Sc. (Phys.-Math.), Assist. Professor, Deputy Head of the Department of Nanoelectronics, Deputy Director of the Physic-Technological Institute MIREA-Russian Technological University (Vernadskogo prospekt 78, Moscow, 119454 Russian Federation).

Ganshina E.A. - Dr. Sc. (Phys.-Math.), Professor, Physical Faculty, Lomonosov Moscow State University (Leninskye gory ul. 1, str. 2, Moscow, 119991 Russian Federation).

Garshin V.V. - Student, Physical Faculty, Lomonosov Moscow State University (Leninskye gory ul. 1, str. 2, Moscow, 119991 Russian Federation).

Semenova D.V. - Student, Department of Nanoelectronics, MIREA-Russian Technological University (Vernadskogo prospekt 78, Moscow, 119454 Russian Federation).

Mirzokulov Kh.B. - Assistant Lecture, Samarkand Branch, Tashkent University of Information Technologies named after Muhammad al-Khwarizmi (Shohruh Mirzo ul. 47A, Samarqand, 140101 Republic of Uzbekistan). 
M.M. Yashin, A.N. Yurasov, E.A. Ganshina, V.V. Garshin

Danilov G.E. - Student, Physical Faculty, Lomonosov Moscow State University (Leninskye gory ul. 1, str. 2, Moscow, 119991 Russian Federation).

\section{Please cite this article as:}

Yashin M.M., Yurasov A.N., Ganshina E.A., et al. Simulation of the spectra of the transverse Kerr effect of magnetic nanocomposites $\mathrm{CoFeZr}-\mathrm{Al}_{2} \mathrm{O}_{3}$. Herald of the Bauman Moscow State Technical University, Series Natural Sciences, 2019, no. 5, pp. 63-72. DOI: 10.18698/1812-3368-2019-5-63-72

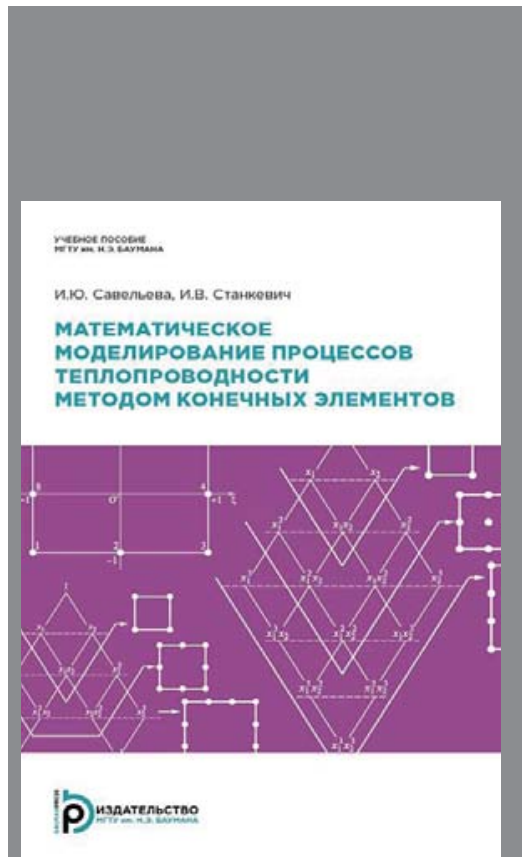

\section{В Издательстве МГТУ им. Н.Э. Баумана} вышло в свет учебное пособие автора

И.Ю. Савельевой, И.В. Станкевича

«Математическое моделирование процессов теплопроводности методом конечных элементов»

Приведены формулировки стационарных и нестационарных задач теплопроводности. Рассмотрены основные особенности построения численного решения этих задач в рамках конечно-элементной технологии.

Для студентов 3-го и 4-го курсов факультета «Фундаментальные науки» МГТУ им. Н.Э. Баумана, изучающих дисциплины «Уравнения математической физики», «Методы вычислений», «Математическое моделирование», «Прикладные пакеты инженерного анализа», «Математические модели механики сплошной среды» и выполняющих соответствующие курсовые работы. Может быть полезно студентам старших курсов других факультетов, изучающим численные методы решения краевых и начально-краевых задач.

По вопросам приобретения обращайтесь:

105005, Москва, 2-я Бауманская ул., д. 5, стр. 1 +7 (499) 263-60-45

press@bmstu.ru http://baumanpress.ru 